\title{
An Experimental Study on Shear Strength Behavior of Soils Under Low Confining Pressure
}

\author{
Eren Balaban'1, Aleš Šmejda1, Mehmet İnanç Onur ${ }^{2}$ \\ ${ }^{1}$ University of Pardubice \\ Studentska 95, 532 10, Pardubice, Czechia \\ eren.balaban@student.upce.cz; ales.smejda@upce.cz \\ ${ }^{2}$ Eskişehir Technical University \\ İki Eylül Campus 26555, Tepebaş1/Eskişehir, Turkey \\ mionur@anadolu.edu.tr
}

\begin{abstract}
Mechanical behavior of soils is highly dependent on their composition. In order to gain better understanding of change in strength parameters according to soil composition, direct shear tests were conducted in this study. Sand was selected as preliminary soil type. Fine grained soil was mixed with sand step by step. Amount of fine grains was increased $10 \%$ in each step. Eleven different mixtures were obtained and standard proctor tests were conducted to determine highest unit weight and optimum water content for each mixture. Then, direct shear tests were conducted for each mixture. Four different confining pressures were chosen, and confining pressures were $9.81 \mathrm{kPa}, 19.62 \mathrm{kPa}, 40.81 \mathrm{kPa}$ and $58.86 \mathrm{kPa}$. Shearing rate was chosen as $0.25 \mathrm{~mm} / \mathrm{min}$ for sandy soils. When the tests were conducted for fine grained soils, shearing rate was chosen as $0.065 \mathrm{~mm} / \mathrm{min}$. Results of this study might help understanding of failure of soil under low confinement.
\end{abstract}

Keywords: Sand, Clay, Direct shear test, Shear strength.

\section{Introduction}

Soils are generally deposited as a mixture in nature because of their formation process. Mixture content may vary according to geological conditions. Many researchers carried out investigations to understand the behavior of mixed soils. Studies can be grouped into two main groups such as gravel sand mixtures and sand clay mixtures. Amir Hamidi et al. (2009) studied the effect of gravel content on shear strength and dilation of sand. It is stated that, addition of gravel into sand increases shear strength due to resistance of gravel grains against rotation. Their study also showed that, dilation increases with gravel content. Haider et al. (2011) investigated the effect of fine sand content in mixture of decomposed granite soil (CDG). It is seen that, when CDG is mixed with fine sand, mixture becomes highly contractive. Researchers also stated that, addition of fine sand develops strong interlocking between particles of mixture which yields increase of shear strength of mixture. Addition of fine sand also increases angle of friction and decreases cohesion of mixture. Hou-Zhen Wei (2018) et al. evaluated mechanical properties of rock sand mixture with variable normal stress and rock percentage using large scale direct shear test. Their study showed that, as rock content increased, shear strength increased under same normal stress conditions. Strain softening behavior is observed under low normal stress, while stress hardening behavior is observed under high normal stress. Stress hardening behavior was more pronounced as rock content increases. Mixtures with higher rock content exhibited more salient dilatant behavior under low normal stress. When normal stress increases, mixtures showed contractive behavior due to breakage of rock grains. Vahidi-Nia (2015) et al. studied participation ratio of fine sand in binary soil. Two types of coarse sand with different particle shape as well as two different fine sands with different gradation are used for their study. Load carrying capacity of sample increases as fine content increases. Their study showed that, load carrying capacity increases more when coarser fine sand in mixed with sub-angular coarse soil. Hamidi et al. (2012) conducted direct shear tests on gravelly sand soils to propose a mathematical relationship to predict angle of friction. Results of the direct shear tests showed that, the highest shear strength is obtained from main soil samples. Shear strength decreased when finer soil is used. Researchers also stated that, when relative density increases, difference between failure envelope of different gradations decreases. Wen-Jie Xu et al. (2015) modelled direct shear tests of soil rock mixtures using discrete element method (DEM). DEM investigation showed that, dilation is higher in case of soil rock mixture than sand soil mixture. 
Because of higher dilation, shear strength of soil rock mixture becomes higher. Dafalla (2013) investigated shear behavior of sand clay mixture by considering effect of clay content and moisture. Results showed that, as clay content increased, shear strength of mixture increased. It is also stated that, as moisture content increases, both angle of friction and cohesion decreases. K. Lini Dev et al. (2016) compared angle of friction computed from triaxial test and direct shear test. They showed that, failure envelopes from triaxial test and direct shear test are equal to each other when silty soil is tested. However, triaxial test results are higher than direct shear test results when clays are tested due to particle orientation. S.S. Najjar et al. (2015) investigated effect of fine content on sand by conducting direct shear test. Maximum fine content is limited to $40 \%$. Researchers concluded that, as fine content increased angle of friction decreases significantly while cohesion increases. Mollins et al. (1999) investigated behavior of bentonite-sand mixtures under drained conditions. They conducted triaxial tests and concluded that, strength of bentonite sand mixture decreases with increasing void ratio of sand. Andrew D. Bro et al. (2013) used different shearing rates in order to find out possibility of using direct shear test to measure undrained strength of clays. Slower tests resulted higher shear strength and contractive behavior than rapid tests. Reason of reduced vertical shear is explained as there is less time to dissipate generated excess pore water pressure. According to this study, if faster shear rate is used, direct shear test would likely underestimate undrained strength. It is also stated that, if normally or lightly over consolidated soils are tested in drained conditions, shear strength would be underpredicted. However, if heavily over consolidated soils are tested in drained conditions, soil strength would be over predicted. Castellanos and Brandon (2013) studied differences between direct shear and triaxial tests in case of clayey soils with undisturbed and remolded soils. In case of undisturbed samples, it is seen that, triaxial tests provided higher angle of friction. In case of remolded samples, angle of frictions found similar. This behavior is attributed to layered soil structure of undisturbed samples. Akayuli et al. (2013) researched effect of clay content to soil strength parameters and compressibility. It is seen that, angle of friction decreases and cohesion increases as clay content increases. It is concluded as plasticity index and compressibility increases as clay content increases. T. Chakraborty and R. Salgado (2010) developed a formula to calculate peak angle of friction and peak angle of dilation regarding relative density and confining stress. Yueru Chen and C. Meehan. (2011) investigated change of strength of bentonite-sand mixtures under different compaction effort, confining stress and bentonite percentage. It is seen that, strength of mixture decreases when water content increases. On the other hand, strength of mixture increases with increasing confining pressure and compacting effort. It is concluded that, samples containing 50\% bentonite are stiffer, stronger and more brittle than samples containing less bentonite. Otoko (2014) investigated effect of clay content on behavior of lateritic soils. Study revealed that, as the clay content increases, angle of friction decreases, cohesion, plasticity index, swelling and shrinkage potential and compressibility increases. A. Sadek et al. (2011) conducted direct shear tests and modelled direct shear test using DEM, it is concluded that, denser and dryer soil has higher shear strength, angle of friction and cohesion. Dafalla and Al-Shamrani (2015) investigated effect of water content to sand-clay mixture with respect to different mixture densities. It is seen that as the water content increases, shear strength of the mixture decreases and even dense mixture behaves like soft mixture. Alshameri et al. (2016) studied effect of coarse materials by using direct shear test. Results showed that, as the percentage of coarse materials increases, shear strength and friction angle decreases, cohesion initially increases and then decreases. Jun-Jie et al. (2013) studied effects of particle size distribution on shear strength of soil considering median particle diameter, coefficient of uniformity and gravel content. Results of both direct shear and triaxial shear tests showed decrease of angle of friction when confining stress increases. Angle of friction increases as median particle diameter increases. Increment in coefficient of uniformity causes reduction of angle of friction. Increasing gravel content also increased angle of friction. Castellanos et al. (2016) investigated fully softened shear strength of soils by conducting direct shear tests. Two new correlations are determined from direct shear test results to predict continuous and nonlinear envelope by using soil index properties. Eid and Rabie (2016) determined fully softened shear strength of clays. Researchers also developed correlation to predict fully softened shear strength of clays using plasticity index. They concluded that, non-linearity on failure envelope is more pronounced under low confining stress. Lade (2009) performed triaxial tests to investigate effect of fine content on void ratio, compressibility and occurrence of static liquefaction. Yimsiri et al. (2013) investigated undrained strength-deformation characteristics of Bangkok clay. Hsiao and Phan (2014) studied effect of silt content on static and dynamic properties of sand. 
Researchers stated that, silt content decreases the angle of friction and increases the cohesion. M.İ. Onur et al. (2014) studied undrained unconsolidated (UU) behavior of saturated clay and modelled UU triaxial test numerically. Experimental results and numerical analysis results matched well in their study. L. Zhang and C. Thornton (2007) modelled direct shear by discrete element method. Jacobson et al. (2007) conducted numerical direct shear test to better understand relationship between sample dimensions and maximum particle diameter. 2D discrete element method is applied in their study.

Although, there are some studies in literature regarding effect of fine content on behavior of sand, but these studies are limited. In this study, fine content is increased from $0 \%$ to $100 \%$ step by step with $10 \%$ increments. Low normal stresses are used during direct shear tests, whose effect is not fully evaluated in literature. $9.81 \mathrm{kPa}, 19.62 \mathrm{kPa}, 40.81 \mathrm{kPa}$ and $58.86 \mathrm{kPa}$ are chosen as normal stresses in this study.

\section{Experimental Program}

The Gradation of sand is determined initially. After that, specific gravity of fine soil is determined along with plastic limit and liquid limit. Sand-fine mixtures are prepared according to mass percentage. Mass of each component is calculated according to total weight of sample. It can be formulized as below.

Fine Mass=Total Weight $* \%$ Fine

Sand Mass $=$ Total Weight $* \%$ Sand

Standard proctor test is conducted in order to determine maximum dry unit weight and optimum water content of all samples. Samples are compacted in three layers. Each layer is tamped 25 times.

Direct shear sample size is equal to $100 \mathrm{~mm} * 100 \mathrm{~mm}$ in cross section. Shearing rate is chosen as $0.25 \mathrm{~mm} / \mathrm{min}$ for samples, which have sand content at least 50\%. Otherwise shearing rate is lowered to $0.065 \mathrm{~mm} / \mathrm{min}$ to allow discharge of excess pore water pressure. Samples are prepared with maximum unit weight. A total number of 44 direct shear tests are conducted for this study.

\subsection{Soil Properties}

Gradation curve of sand after sieve analysis is given in Figure 1 below. According to Figure 1 uniformity coefficient and coefficient of gradation is calculated as 3.3 and 0.842 respectively. Sand is classified as SP according to unified classification system.

Specific gravity of fine soil is measured as 2.69 according to ASTM D854. Plasticity limit is determined according to ASTM D4318 as $20.18 \%$. Liquid limit is calculated by using fall cone test as $35.86 \%$.

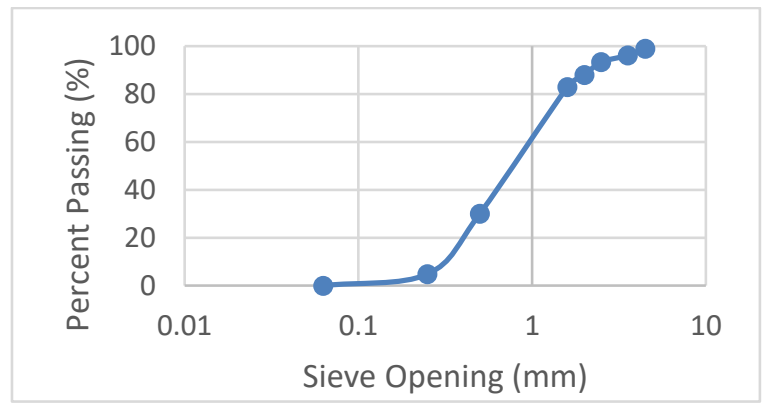

Fig. 1: Gradation curve for sand.

Standard proctor test is conducted for every mixture. Maximum dry unit weight and optimum water content is given in Table 1 for every mixture. Standard proctor test is usually does not conducted for sands. However, in some cases, for example during construction of retaining and mechanically stabilized walls. U.S Department of Transportation Federal Highway Administration (FHWA) (2009) says that, 95\% of standard proctor compaction should be achieved with $\pm 2 \%$ of optimum water content. Some researchers are used standard proctor test to determine maximum dry unit weight and optimum water 
content of sand and gravel $(31,32,33)$. Das Braja (2010) also provided a dry unit weight and moisture content graphic for various types of soil, which includes poorly graded sand.

Table 1: Maximum dry unit weight and optimum water content of mixture.

\begin{tabular}{|l|c|c|}
\hline Mixture & $\begin{array}{c}\text { Maximum Dry Unit Weight } \\
\left(\mathbf{g} / \mathbf{c m}^{\mathbf{3}}\right)\end{array}$ & $\begin{array}{c}\text { Optimum Water Content } \\
\mathbf{( \% )}\end{array}$ \\
\hline 100\% Sand & 1,74 & 11,5 \\
\hline 90\% Sand + 10\% Fine & 1,80 & 9,5 \\
\hline 80\% Sand + 20\% Fine & 2,07 & 8,0 \\
\hline 70\% Sand + 30\% Fine & 2,13 & 6,8 \\
\hline 60\% Sand + 40\% Fine & 2,05 & 8,0 \\
\hline 50\% Sand + 50\% Fine & 2,12 & 8,6 \\
\hline 40\% Sand + 60\% Fine & 2,06 & 9,1 \\
\hline 30\% Sand + 70\% Fine & 2,02 & 10,0 \\
\hline 20\% Sand + 80\% Fine & 2,00 & 11,0 \\
\hline 10\% Sand + 90\% Fine & 1,99 & 10,0 \\
\hline 100\% Fine & 1,85 & 12,5 \\
\hline
\end{tabular}

Maximum dry unit weight increases up to threshold value of fine content in mixture. After threshold value, maximum unit weight decreases. Only 50\% sand $+50 \%$ fine mixture does not follow this behavior. Similar trend is observed for optimum water content. It is seen that; optimum water content decreases as fine content increases up to $70 \%$ sand $+30 \%$ fine. This behavior is not followed in case of $10 \%$ sand $+90 \%$ fine soil mixture. Reason of those behavior may be explained as, in initial stages of sand fine mixtures, fine particles fills voids. Since void ratio is lower, maximum dry unit weight increases. Since void ratio is lower in mixtures, less water is required to compact soil particles. However, when mixture behavior is governed by fine particles, void ratio tends to increase again, therefore maximum unit weight starts to decrease and optimum water content increases.

\section{Test Results}

\subsection{Direct Shear Test}

Das Braja (2008) defines two types of angle of friction according to its determination as peak friction angle and ultimate angle of friction. Those peak angle of frictions are determined from graphic of peak shear strength and corresponding normal stress. Ultimate angle of friction is determined by using ultimate shear strength and corresponding normal stress. Ultimate shear stress corresponds to the shear stress where, volume of the sample remains constant during shearing. According to FHWA (2009), peak shear strength values are used in wall and slope analysis. Therefore, peak shear strength values are used in this study to determine angle of friction. Several researchers in literature also used peak shear strength to determine angle of friction $[5,7,36,37,38,39.40,41,42,43]$.

Direct shear tests revealed that, as normal stress increases, shear strength of samples increase for all mixtures. All mixtures are prepared in maximum dry unit weight and tested at low normal stress. These conditions provide over consolidation condition. Due to over consolidation condition, a peak shear stress is observed and it is followed by stress softening with shear strain.

Shear strength of mixtures tends to increase with fine content. This increase is more pronounced in case of low normal stress. Maximum shear stress is measured as $11 \mathrm{kPa}$ and $65.3 \mathrm{kPa}$ under $9.81 \mathrm{kPa}$ and $58.86 \mathrm{kPa}$ normal stresses in case of sand sample. When fine sample is tested, it is seen that, maximum shear strength increased to $44.6 \mathrm{kPa}$ and $76.6 \mathrm{kPa}$. In order to better observe and understand change of shear strength with respect to normal stress and fine soil content, stress ratio (SR) is calculated for each test. SR may be computed as follows. 


$$
S R=\frac{\tau_{\max }}{\sigma}
$$

Each calculated SR is shown on Fig. 2, where x-axis shows increase on sand content and y-axis shows SR. SR increases as sand content decreases. However, at some points for all normal stresses considered, SR tends to decrease after initial increase. However, this decrease is only temporary and SR continues to increase after that point. Increase of SR becomes more pronounced as normal stress decreases and fine content increases. As can be seen from Fig. 2, SR is almost equal for $90 \%$ sand $10 \%$ fine mixture and sand sample regardless of normal stress. This is due to, for those samples, shear strength is provided by friction forces between sand particles.

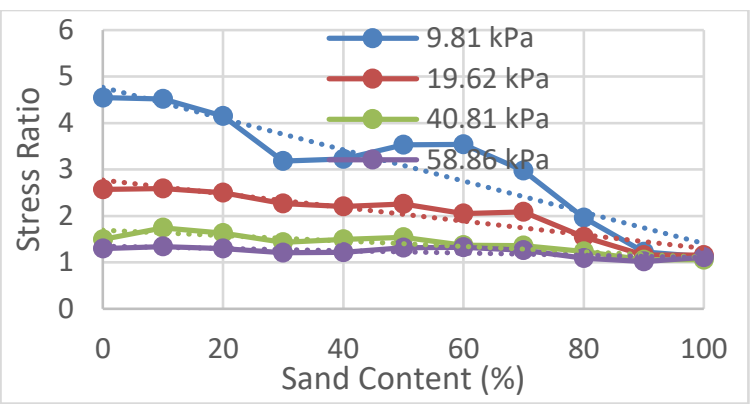

Fig. 2: Stress Ratio for different normal stress and fine content.

As amount of fine particles increase in sample, SR increases and increment is more pronounced for low normal stress. The reason of this behavior can be summarized as follows. As fine content increases, cohesion gets larger and it contributes to shear strength significantly. Since cohesion is independent from normal stress, SR increases more for low normal pressures.

Samples initially shows contractive behavior, then it is followed by dilatation. Vertical displacement-horizontal displacement graphics are provided as an example on Fig. 3.

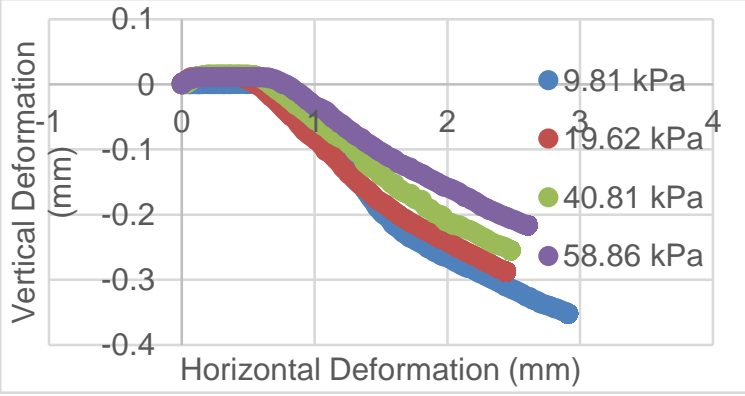

(a) $30 \%$ Sand $+70 \%$ Fine Soil

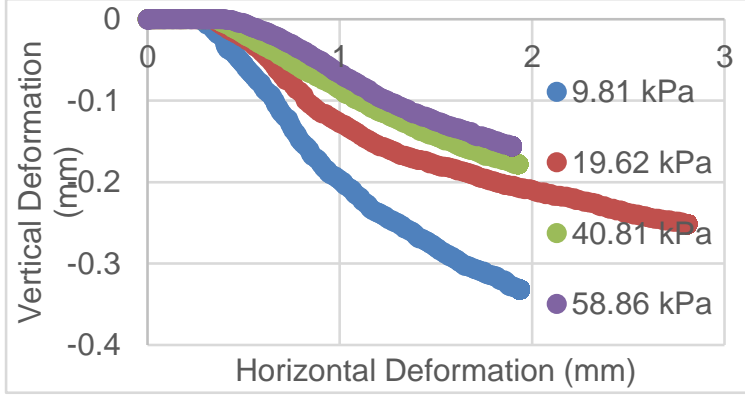

(b) Fine Soil

Fig. 3: Dilatancy behavior of samples.

Maximum angle of friction is measured for sand sample as expected. Measured maximum angle of friction equals to 47.38. Angle of friction decreases as fine content increases. Angle of friction decreases to 32.44 degrees for fine soil. Change of angle of friction is given on Fig. 4 with respect to sand content. Measured angle of friction might be an unconventional value. However, similar values are also reported in the literature for sands. For example, Huabei Liu (2012) reported angle of friction by conducting triaxial test of different soil under $30 \mathrm{kPa}$ confining stress between $37^{0}$ to $47^{0}$. Similarly, S. Bali Reddy and A. Murali Krishna (2015) reported $48^{\circ}$ angle of friction of sand. R. Bathurst et al. (2005) collected data from 
several case studies from the literature. They concluded that, angle of friction of sand varies between $39^{0}$ and $49^{0}$ degrees. Therefore, angle of friction found in this study is in range of values reported in literature for angle of friction of sands.

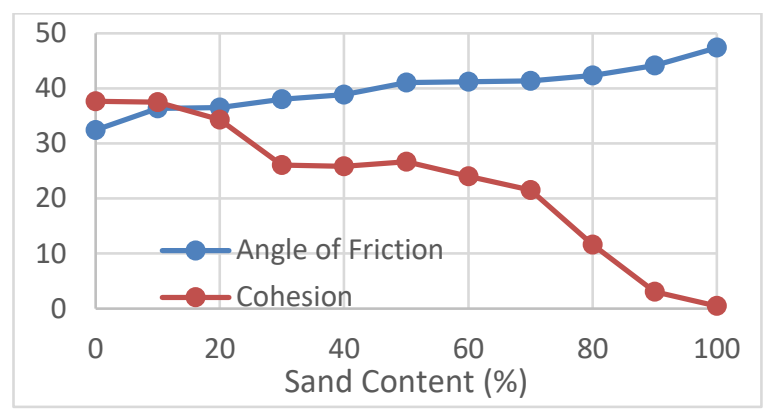

Fig. 4: Change of angle of friction and cohesion with sand content.

Cohesion of fine soil is found to be $37.66 \mathrm{kPa}$ and it decreased to $0.46 \mathrm{kPa}$ for sand. No cohesion is observed for dry sandy soils however, when sand is mixed with water, some cohesion value is obtained after direct shear test. Cohesion of sands are called as apparent cohesion and arises due to surface tension of moisture film surrounding each particle. Apparent cohesion should not be above $2 \mathrm{kPa}$, otherwise it is an indication of error during test. Change of cohesion is also shown on Fig. 4 with respect to sand content. There is a small reduction for cohesion between $30 \%$ and $50 \%$ sand. Reduction of cohesion in that interval can be due to change of shearing rate. Sample with $50 \%$ sand content was sheared by $0.25 \mathrm{~mm} / \mathrm{min}$ while $40 \%$ and $30 \%$ sand content was sheared by $0,065 \mathrm{~mm} / \mathrm{min}$. It is well known that, increased shear rate increases shear strength of samples which may have caused minor inconsistency of cohesion values for this study.

\section{Conclusion}

44 direct shear tests are conducted to study change of behavior of sand fine soil mixtures under low normal stress. Results of this study can be summarized as follows.

- Maximum dry unit weight increases up to threshold value of fine content. Maximum dry unit then starts to decrease after that threshold value.

- Optimum water content decreases until threshold value of fine content. After threshold, required water content to achieve maximum dry unit weight increases.

- Shear strength increases as both fine content and normal stress increases. Shear strength increase becomes more pronounced in case of lower normal stress.

- Dilative behavior is observed after initial contraction of samples. Contraction of samples are observed to be so small with respect to their expansion.

- Angle of friction increases and cohesion decreases as sand content increases. Constant value of cohesion is observed when shearing rate is decreased.

\section{Acknowledgements}

This article is supported by University of Pardubice with a project ID SGS_2017_009.

\section{References}

[1] K. A Amir Hamidi, Vahid Yazdanjou, and Nima Salimi, "Shear strength characteristics of sand-gravel mixtures," International Journal of Geotechnical Engineering, vol. 3, no. 1, pp. 29-38, 2009.

[2] Haider, M. Mekkiyah, Huat B. B. K, M. A. Malek and Mohd Noor Dis. "Effect of mixing fine sand on the drained shear strength of completely decomposed granite soil," Int. J. of Geomate, vol. 1, no. 1, pp. 10-18, 2011. 
[3] Hou-Zhen Wei, Wen-Jie Xu, Xiao-Feng Xu, Qing-Shan Meng, and Chang-Fu Wei, "Mechanical properties of strongly weathered rock-soil mixtures with different rock block contents," Int. J. Geomech., vol. 18, no 5, pp. 1-12, 2018.

[4] F. Vahidi-Nia, A. Lashkari, S. M. Binesh, "An insight into the mechanical behavior of binary granular soils," Particuology, vol. 21, pp. 82-89, 2015.

[5] A. Hamidi, E. Azini, B. Masoudi, "Impact of gradation on the shear strength-dilation behavior of well graded sandgravel mixtures," Scientia Iranica, Transactions A: Civil Engineering, vol. 19, no. 3, pp. 393-402, 2012.

[6] Wen-Jie Xu, Cheng-Qing Li and Hai-Yang Zhang, "DEM analyses of the mechanical behavior of soil and soil-rock mixture via the 3D direct shear test," Geomechanics and Engineering, vol. 9, no. 6, pp. 815-827, 2015.

[7] Muawia A. Dafalla, "Effects of clay and moisture content on direct shear tests for clay-sand mixtures," Advances in Materials Science and Engineering, pp. 1-8, 2013.

[8] K. Lini Dev, Rakesh J. Pillai and Retnamony G. Robinson, "Drained angle of internal friction from direct shear and triaxial compression tests," International Journal of Geotechnical Engineering, vol. 10, no. 3, pp. 283-287, 2016.

[9] S. S. Najjar, K. Yaghi, M. Adwan and A. A. R. A. Jaoude, "Drained shear strength of compacted sand with clayey fines," International Journal of Geotechnical Engineering, vol. 9, no. 5, pp. 513-520, 2015.

[10] L. H. Mollins, D. I. Stewart and T. W. Cousens, "Drained strength of bentonite-enhanced sand," Geotechnique, vol. 49, no. 4, pp. 523-528, 1999.

[11] Andrew D. Bro, Jonathan P. Stewart and Daniel Pradel, F. "Estimating undrained strength of clays from direct shear testing at fast displacement rates," in Geo-Congress, San Diego, California, 2013, ASCE, pp. 106-119.

[12] Castellanos B.A., Brandon T.L., "A comparison between the shear strength measured with direct shear and triaxial devices on undisturbed and remolded soils," in Proceedings of the 18th International Conference on Soil Mechanics and Geotechnical Engineering, Paris, France, 2013, pp. 317-320.

[13] Cfa Akayuli, Bernard Ofosu, Seth O. Nyako, Kwabena O. Opuni, "The influence of observed clay content on shear strength and compressibility of residual sandy soils," International Journal of Engineering Research and Applications, vol. 3, no. 4, pp. 2538-2542, 2013.

[14] T. Chakraborty and R. Salgado, "Dilatancy and shear strength of sand at low confining pressures," J. of Geotech. Geoenviron. Eng., ASCE, vol. 136, no. 3, pp. 527-532, 2010.

[15] Yueru Chen and Christopher L. Meehan, "Undrained strength characteristics of compacted bentonite/sand mixtures," in Geo-Frontiers, Dallas, Texas, 2011, pp. 2699-2708.

[16] George Rowland Otoko, "Dependence of shear strength and compressibility of tropical lateritic soils on clay content," International Journal of Engineering and Technology Research, vol. 2, no. 2, pp. 1-9, 2014.

[17] Mohammad A. Sadek, Ying Chen and Jude Liu, "Simulating shear behavior of a sandy soil under different soil conditions," Journal of Terramechanics, vol. 48, no. 6, pp. 451-458, 2011.

[18] Muawia Dafalla and Mosleh Al-Shamrani, "Assessment of shear failure parameters for sand-clay liners," in IFCEE, San Antonio, Texas, 2015, ASCE, pp. 1826-1833.

[19] B. Alshameri, I. Bakar, A. Madun, L. Abdeldjouad and S. Haimi Dahlan, "Effect of coarse materials percentage in the shear strength," in IOP Conf. Ser.: Mater. Sci. Eng., Lankawi, Malaysia, 2015, vol. 136.

[20] Jun-Jie Wang, Hui-Ping Zhang, Sheng-Chuan Tang, and Yue Liang "Effects of particle size distribution on shear strength of accumulation soil," J. Geotech. Geoenviron. Eng., vol. 139, no. 11, 2013.

[21] B. A. Castellanos, T. L. Brandon, and D. R. VandenBerge, "Correlations for fully softened shear strength parameters," Geotechnical Testing Journal, vol. 39, no. 4, pp. 568-581, 2016.

[22] Hisham T. Eid and Khaled H. Rabie, "Fully softened shear strength for soil slope stability analyses," Int, J. Geomech., vol. 17, no. 1, 2016.

[23] Poul V. Lade, Jerry A. Yamamuro and Carl D. Liggio, Jr, "Effects of fines content on void ratio, compressibility, and static liquefaction of silty sand," Geomechanics and Engineering, vol. 1, no. 1, pp. 1-15, 2009.

[24] Siam Yimsiri, Wanwarang Ratananikom, Fumihiko Fukuda and Suched Likitlersuang, "Undrained strengthdeformation characteristics of Bangkok Clay under general stress condition," Geomechanics and Engineering, vol. 5, no. 5, pp. 419-445, 2013. 
[25] Darn H. Hsiao and Vu T. A. Phan, "Effects of silt contents on the static and dynamic properties of sand-silt mixtures," Geomechanics and Engineering, vol. 7, no. 3, pp. 297-316, 2014.

[26] M. Inanc Onur, Burak Evirgen, Ahmet Tuncan and Mustafa Tuncan, "Modelling of shear strength parameters of saturated clayey soils," Int. J. of Geomate, vol. 7, no. 2, pp. 1107-1110, 2014.

[27] Douglas E. Jacobson, Julio R. Valdes, and T. Matthew Evans, "A numerical view into direct shear specimen size effects," Geotechnical Testing Journal, vol. 30, no. 6, pp. 512-516, 2007.

[28] ASTM D854 (2014), Standard test methods for specific gravity of soil solids by water pycnometer.

[29] ASTM D4318 (2010), Standard test methods for liquid limit, plastic limit, and plasticity index of soils.

[30] FHWA, "Design and construction of mechanically stabilized earth walls and reinforced soil slopes-volume 1," publication no. FHWA-NHI-10-024, 2009.

[31] E. Bourgeois, L. Soyez and A. Le Kouby, "Experimental and numerical study of the behaviour of a reinforced-earth wall subjected to a local load," Computers and Geotechnics, vol. 38, pp. 515-525, 2011.

[32] Guangqing Yang, Junxia Ding, Qiaoyong Zhou and Baojian Zhang, "Field behaviour of a geogrid reinforced retaining wall with a wrap-around facing," Geotechnical Testing Journal, vol. 33, no. 1, pp. 1-6, 2010.

[33] Chungsik Yoo, "Performance of a 6-year-old geosynthetic- reinforced segmental retaining wall," Geotextiles and Geomembranes, vol. 22, pp. 377-397, 2004.

[34] Braja M. Das, Principles of Geotechnical Engineering. Seventh Ed., Stamford: Cengage Learning, pp. 366-367, 2010.

[35] Braja M. Das, Advanced Soil Mechanics. Third Ed., New York: Taylor and Francis, pp. 119, 2008.

[36] Ayşe Edinçliler, Gökhan Baykal, Altug Sayg1l1, "Influence of different processing techniques on the mechanical properties of used tires in embankment construction," Waste Management, vol. 30, pp. 1073-1080, 2010.

[37] G. Venkatappa Rao, R.K. Dutta "Compressibility and strength behaviour of sand-tyre chip mixtures," Geotechnical and Geological Engineering, vol. 24, pp. 711-724, 2006.

[38] M. Neaz Sheikh, M. S. Mashiri, J. S. Vinod and Hing-Ho Tsang, "Shear and compressibility behaviour of sand-tire crumb mixture,” J. Mater. Civ. Eng., vol. 25, pp. 1366-1374, 2013.

[39] Gary J. Foose, Craig H. Benson and J. Bosscher, "Sand reinforced with shredded waste tires," J. Geotech. Engrg., vol. 122, pp. 760-767, 1996.

[40] P. Anbazhagan, D. R. Manohar and Divyesh Rohit, "Influence of size granulated rubber and tyre chips on the shear strength characteristics of sand-rubber mix," Geomechanics and Geoengineering: An International Journal, vol. 12, no.4, pp. 266-278, 2017.

[41] Richard J. Bathurst, Tony M. Allen, Dave L. Walters, "Reinforcement loads in geosynthetic walls and the case for a new working stress design method," Geotextiles and Geomembranes, vol. 23, pp.287-322, 2005.

[42] Huabei Liu, "Long-term lateral displacement of geosynthetic-reinforced soil segmental retaining walls," Geotextiles and Geomembranes, vol. 32, pp. 18-27, 2012.

[43] S. Bali Reddy, A. Murali Krishna, "Recycled tire chips mixed with sand as lightweight backfill material in retaining wall applications: An experimental investigation," Int. J. of Geosynth and Ground Eng., pp. 1-31, 2015. 